\section{MODELOS NORMATIVOS DE SOCIEDAD Y MIGRACIONES*}

\author{
Ermanno Vitale \\ Università della Valle d'Aosta
}

\begin{abstract}
The aim of the essay is to outline the possible relations between, on one hand, the main normative models of society in Western political thought and on the other hand the ways migration has been addressed in theoretical terms. First, we look at the complex and contradictory connections between migration and models of society in Plato and Aristotle. Secondly, we examine how the relationship between citizenship and migration has been understood within the framework of individualism and contract theory (foremost in Hobbes, Locke and Kant). In section three, the theme is illustrated from the perspective of some of today's normative political theories (neo-utilitarism, communitarism, neo-republicanism, constitutionalism centred on fundamental rights). Here some critical arguments in favour of residence-based citizenship entitlement and the right to migrate are discussed.
\end{abstract}

KEY WORDS: Citizenship; migration; holism; individualism.

\section{INTRODUCCIÓN}

En el primer capítulo de la Teoría general de la política Norberto Bobbio (2002) distingue cuatro tipos de filosofía política. El primero consiste en el diseño y teorización de la óptima república, esto es, de un modelo ideal de Estado que asegure no sólo las condiciones para una convivencia segura y pacífica, sino también las condiciones de una convivencia conforme a la justicia (el ejemplo obvio es Platón). El segundo tipo se centra en la búsqueda del fundamento último del poder, en su legitimidad, en las razones para la obediencia, o sea, intenta responder a preguntas como "¿por qué, bajo qué condiciones y a quién debo obedecer?" (el ejemplo es Hobbes y el contractualismo moderno). El tercer tipo se centra en la determinación del "concepto de lo político", en la autonomía de su esfera y, en particular, en la distinción entre política y moral (Maquiavelo); por último, un cuarto y más reciente tipo de filosofía política se presenta como metateoría, como discurso crítico sobre

\section{NORMATIVE MODELS OF SOCIETY AND MIGRATION}

RESUMEN: Este ensayo se propone delinear las relaciones que pueden darse entre algunos de los principales modelos normativos de sociedad que es posible encontrar en el pensamiento político occidental y las distintas maneras en que son afrontados, en perspectiva teórica, los fenómenos migratorios. En la primera parte, el ensayo se detiene sobre las complejas y contradictorias relaciones que existen entre modelos de sociedad y migraciones en Platón y Aristóteles, mientras que en la parte central, la atención se centra en el planteamiento individualista y contractualista de la relación entre ciudadania y migraciones (Hobbes, Locke y Kant, en particular). Finalmente, se toma en consideración la perspectiva que aportan algunas teorias normativas contemporáneas (neo-utilitarismo, comunitarismo, neo-republicanismo y constitucionalismo de los derechos fundamentales) y se presentan, de forma critica, algunos argumentos a favor de la ciudadanía por residencia y del derecho a migrar.

PALABRAS CLAVE: Ciudadania; migración; holismo; individualismo.

los criterios de validez y sobre los presupuestos metodológicos de la ciencia política, la cual, por su parte, se encarga de llevar a cabo estudios empíricos sobre los fenómenos políticos. Bobbio observa sin embargo, enseguida, que los tres primeros tipos - pero no el cuarto, sobre el que no se pronuncia, por entender que es más una propuesta que una realidad- tienen una constante dimensión normativoprescriptiva, expresada a veces de forma enfática, como sucede en el caso del pensamiento utópico, y otras no, como en los otros dos tipos de filosofía política. Uno de los problemas característicos del pensamiento contractualista es saber si existe o no un deber de obediencia al orden injusto: la cuestión de la justicia, del orden social justo, acaba saliendo a relucir. Se encuentra incluso en los realistas políticos como Maquiavelo, para quien la Roma republicana es algo más que un ejemplo de estabilidad y permanencia de una determinada organización del poder, esto es, un ejemplo de éxito, sino que representa también un modelo de orden político justo, un modelo normativo. 
Lo que intentaré delimitar en este ensayo es la relación que existe -de forma explícita y, más frecuentemente, de forma implícita- entre la búsqueda de la "sociedad justa" en algunos autores significativos (naturalmente, no en todos) del pensamiento político occidental con el hecho de la migración y con el juicio sobre la misma. El recorrido comienza inevitablemente con Platón y requiere una obvia precisión sobre Aristóteles, el otro autor pre-moderno del que me voy a ocupar: a falta de una teoría de los derechos subjetivos universales, la relación que podemos tomar en consideración es la que se establece entre los modelos de sociedad justa y la función y/o valoración del fenómeno migratorio, pero no es posible contemplar la perspectiva de un "derecho a migrar".

\section{Ambigüedades platóNICAS...}

En los tres diálogos dedicados a la política -el Político, la República y las Leyes- la actitud y el juicio implícito de Platón sobre la migración es ambivalente. De un lado, en efecto, tanto en el Político como en las Leyes, la migración no sólo favorece y acompaña, sino que es considerada como conditio sine qua non para realizar en positivo y en negativo el proceso de pre-selección estrictamente moral -y no étnico-cultural o censitaria- de los seres humanos que, si es llevada a efecto con habilidad, tiene como resultado final una sociedad bien ordenada (aquélla en la que el político-tejedor sabe entrelazar en la justa medida los dos impulsos que poseen los ciudadanos, la urdimbre del valor militar y el entramado del decoro, de la vida productiva y tranquila). Para ello, sin embargo, es necesario llevar a cabo una operación previa de separación física de quienes no sean aptos para ser educados, para convertirse en tejedores:

no es de temer que la política para nosotros verdadera y ajustada a naturaleza [se lee en la conclusión del Político (308d-309a)] vaya jamás de buen grado a basarse en hombres buenos y malos para constituir una ciudad, sino que está bien patente que los probará primero con un juego, y después de la prueba los entregará a los capacitados para educar y servir a esa misma función [...]; mas, a quienes resulten incapaces de compartir un carácter valeroso y prudente, y las demás tendencias que conducen a la virtud, antes bien, se dejan arrastrar a la impiedad, la insolencia y la injusticia movidos por la violencia de un perverso natural, el arte real los rechaza, condenándolos a muertes, destierros y los más infamantes castigos.

En el Político, el exilio, la migración forzosa es, en negativo, el medio que permite separar a quienes pueden ser sometidos al proyecto pedagógico-político platónico de quienes, por el contrario, son constitutivamente inadecuados para ese fin. Los moralmente incorregibles son apartados. En las Leyes, la perspectiva sigue siendo la misma, pero los que migran son los buenos, hasta el punto que en la edificación de una ciudad justa, aunque con un grado de perfección menor que en la Kallipolis de la República, se remite a la hipotética fundación de una colonia:

La mayor parte de las ciudades de Creta emprenden la fundación de una colonia [explica Clinias a los otros dos personajes, el espartano Megilo y el huésped ateniense] y han encomendado a los Cnosios hacerse cargo del asunto. A su vez, la ciudad de Cnosos me lo ha encargado a mí y a otros nueve; al mismo tiempo, nos manda que promulguemos aquellas leyes de nuestro país que sean de nuestro agrado, o bien las de cualquier otro sitio, sin tener en cuenta lo extrañas que sean con tal de que nos parezcan mejores (III, 702c).

Leyes que no tienen por qué ser las de la patria, por tanto, pero sí leyes buenas, por más que deriven de otros ordenamientos: eso es lo que pretenden dar al nuevo estado los tres interlocutores. Será una colonia fundada por cretenses, pero no tendrá por qué reproducir la cultura, al menos la cultura jurídica, de la ciudad de origen. Y si el nuevo estado quiere ser mejor que la madre patria, si quiere enmendar sus defectos, lo primero que tendrá que hacer es impedir "que vayan a él toda la gente malvada que hay entre quienes pretenden entrar en el nuevo estado" ( $V, 736 \mathrm{c})$. Así entendida, aun no siendo un comienzo absolutamente nuevo, la migración es un potente factor de renovación moral y cultural de las sociedades, que no es obstáculo, sino, al contrario, refuerzo de la cohesión y la armonía. Bien seleccionados, los cretenses de la colonia constituirán, gracias también a la presencia de leyes "extranjeras" $y_{1}$ en parte, distintas a las de la patria, una comunidad mejor, menos corrupta, que la de origen.

Opuesta -dominada por la preocupación de seleccionar a los mejores, a los gobernantes y guardianes dentro de un grupo autóctono- es por el contrario la actitud de 
Platón en la República, como puede verse a través del célebre mito de los metales de los que están formados los distintos miembros de aquella comunidad en la que se realiza la justicia entendida como oikeiopragia (cada uno debe desarrollar en y para la polis la tarea para la que el talento natural le predispone, 434c). Pero ya desde el comienzo, la ambientación del diálogo -Sócrates desciende al Pireo, descrito como lugar-símbolo de la confusión que reina en la Atenas democrática de la época, un infierno del que hay que ascender hasta diseñar la ciudad ideal $y_{\text {, }}$ no en vano, un infierno que Paul Friedländer ha definido como el primer melting-pot de la historia- indica el desorden que genera la mezcla de culturas derivada de fenómenos migratorios (del mar proviene una multitud desordenada de malas costumbres) y que la polis ideal habrá de evitar. El mito de los metales (oro para los gobernantes, plata para los guardianes, bronce y hierro para campesinos y artesanos) que apunta la idea según la cual la sociedad justa es aquélla en la que cada cual hace lo que le corresponde, está presuponiendo en su aceptación la necesidad de la "noble mentira" sobre el origen común de los ciudadanos:

la tierra, su madre, los sacó a la luz, por lo cual deben ahora preocuparse de la ciudad en que moran como de quien es su madre y nodriza y defenderla si alguien marcha contra ella y tener a los restantes ciudadanos por hermanos suyos, hijos de la misma tierra. [...] Sois, pues, hermanos todos cuantos habitáis en la ciudad -les diremos siguiendo con la fábula- (414e-415a).

En el fondo, el núcleo ideológico del nacionalismo está enteramente contenido ya en esta noble mentira: cada miembro tiene especiales deberes hacia sus "hermanos" y esta pertenencia de estirpe está por encima tanto de cualquier otra pertenencia de clase o de casta, como de la consideración del otro como miembro de la comunidad humana universal. Es superfluo añadir que en esta perspectiva la migración, que trae consigo la mezcla de culturas representada simbólicamente por el puerto del Pireo, es considerada como el origen del mal por excelencia en la reflexión política occidental: inestabilidad, confusión, desorden interno (inseguridad y miedo individuales y colectivos, y las correspondientes psicosis) están en el origen del cambio político violento y repentino, esto es, de un remedio que es peor que el mal, la aparición de un tirano que promete restablecer el orden en la ciudad.
Con un gran salto hacia delante en el tiempo -quizá incorrecto desde el punto de vista historiográfico pero útil para ilustrar la persistencia en el tiempo del miedo al otro, un miedo que se presenta paradójicamente como el único elemento "cosmopolita" de la historia de la humanidad-, el temor al caos derivado de la mezcla en el Pireo y la demanda de pureza (un pueblo, un territorio, una cultura, un estado-nación) retorna en la filosofía política romántica a comienzos del siglo diecinueve. Valga aquí una cita clásica de Hegel, que sintetiza y reformula el pensamiento holístico-organicístico de los diversos autores de la Romantik, Novalis, los hermanos Schlegel, Müller:

El Estado es la realidad inmediata de un pueblo particular y naturalmente determinado. Como el individuo particular, es exclusivo respecto de los demás individuos semejantes. En el comportamiento recíproco entre estos [Estados] se da el arbitrio y la accidentalidad. [...] Esta independencia convierte la lucha entre ellos en una relación de fuerza, en una condición de guerra (Hegel, Enciclopedia, § 545).

Aun sin ceder a la tentación de las ecuaciones simplistas, creo indiscutible que cuanto mayor sea el énfasis en los elementos étnico-naturalistas (o de esa segunda naturaleza que es la cultura como conjunto de lengua y tradiciones) en la formación, delimitación e "identidad" de un Estado, menor será la disposición a considerar la migración como un fenómeno fisiológico y a reconocerles a los individuos un derecho a ella, un derecho al que se asocia la idea de una ciudadanía basada en la residencia y en la lealtad a una constitución de contenido universalista. Como fisiológico es también el conflicto, y en última instancia la guerra, entre Estados-comunidad que consideran la pertenencia de los individuos como necesaria y que actuando como macro-sujetos naturales compiten incesantemente por recursos y espacios vitales.

\section{3. ... Y ARISTOTÉLICAS}

Pero detengámonos un momento más en la filosofía griega para echar una mirada al pensamiento político de Aristóteles. Aquí también están esbozadas, en materia de ciudadanía y migración, dos líneas de desarrollo ambiguas, cuando no contradictorias, que iban a convertirse en temas recurrentes en el pensamiento político occidental. La 
primera es extremadamente innovadora frente a la idea étnico-culturalista de polis. Interrogándose sobre la definición del ciudadano, Aristóteles descarta inmediatamente este tipo de respuesta:

\begin{abstract}
Algunos llevan aún más lejos la investigación de este aspecto, por ejemplo hasta dos, tres o más antepasados. Pero al dar una definición tan política y estricta, pronto se preguntarán algunos cómo será ciudadano aquel tercero o cuarto antepasado. Gorgias de Leontinos, quizá porque no veía solución o por ironía, dijo que igual que morteros son los fabricados por los fabricantes de morteros, así también son los lariseos los fabricados por algunos demiurgos; pues los hay que son fabricantes de lariseos (Politica, III, 1275b).
\end{abstract}

La ciudadanía es, por tanto, un producto político artificial, que depende de la forma de gobierno y de las normas que se hayan dado a sí mismas las colectividades políticas: en cualquier polis, sugiere Aristóteles, es ciudadano quien participa en las funciones de juez y en cargos públicos. La definición misma de la ciudadanía basada en la descendencia (ius sanguinis) o en el nacimiento dentro de las fronteras de la ciudad (ius soli) puede ser reconducida a una decisión política y no depende de un dato natural, sino de los criterios de inclusión y exclusión, siempre revisables, que el legislador haya querido establecer artificialmente. La ciudadanía por residencia, que es la otra cara del derecho a la migración, encuentra así en el fragmento de la Política en que se argumenta a favor del carácter convencional de la definición del ciudadano sus raíces más lejanas. Pero en Aristóteles aparece también un criterio natural rígido de inclusión/exclusión basado en la naturaleza de los individuos y los pueblos. Existen individuos y pueblos siervos por naturaleza, incapaces de tener autonomía y juicio: en el mundo griego, y en general en el mundo de los pueblos libres, estos individuos serán esclavos por naturaleza; cuando pueblos enteros son siervos por naturaleza surgirá la forma política del despotismo, la única adecuada para ellos 0, mejor dicho, la que les es propia por naturaleza. Una especie de tiranía perpetua y legitimada por el hecho de que los pueblos bárbaros, al contrario de los griegos que son amantes de la libertad, al menos la soportan bien.

Como es evidente, la categoría del "despotismo oriental" que, partiendo de Aristóteles y pasando por Maquiavelo, Bodino y Montesquieu llega a Hegel y a nuestros días, no tiene un significado histórico-geográfico preciso y se extiende a todo aquello que no es Europa (¿Occidente?), constituyendo uno de los pilares de lo que Bobbio ha definido como la "ideología europea", formada precisamente en contraste-oposición con el mundo oriental, símbolo del otro que resulta ajeno, de lo diferente y extraño. Reformulada en los términos que aquí nos interesan, podríamos decir quizá que la artificialidad de la ciudadanía y la posibilidad de ponerla en relación con la mera residencia estable queda en todo caso delimitada por elementos naturales 0 , si se prefiere decir así, étnico-culturales. La insistente demanda de reconocimiento de las raíces judeocristianas, fundamentalmente cristianas, de Europa -que aparece en el momento en que se divisa la posibilidad de dotar a la Unión Europea de un tratado constitucional (por más que éste sea un oxímoron)- ilustra a la perfección la duración y la persistencia, si bien con variaciones de matiz, de esta delimitación fundamentalmente cultural de la "fortaleza Europa". De un lado, dicha delimitación cultural está en el trasfondo de la equiparación, al menos en la teoría, de las migraciones entre los países de la Unión con las dramáticas migraciones de ciudadanos que transformaron Italia en los años sesenta y setenta del siglo pasado; de otro lado, constituye el presupuesto, más o menos implícito, de la exclusión social y de la consideración en términos de mera fuerza-trabajo de aquellas personas que no tienen nuestras mismas "raíces".

\section{El contractualismo moderno y la ciudadanía POR RESIDENCIA}

La ausencia de referencias a la categoría del despotismo oriental puede ser considerada como un test para diferenciar, en la historia del pensamiento político occidental, un modelo distinto para la construcción de la convivencia civilizada $y$, en cierta medida, de la sociedad justa. Si no me equivoco, en los grandes autores que solemos asociar con el contractualismo moderno no aparece ningún análisis ni desarrollo del tema del despotismo oriental. Aun siendo indiscutible que ese modelo es fruto de la cultura occidental o, como dirían algunos, occidentocéntrico, es innegable que en dicho modelo la premisa para responder a la pregunta acerca de las condiciones para la construcción, en primer lugar, de un orden político $y$, en segundo lugar, de un orden político justo, no contienen referencia alguna a elementos de carácter étnico-naturalista de los 
que deriven exclusiones/inclusiones establecidas a priori. El punto de partida de la reflexión sobre la obligación de obediencia y sobre los fundamentos de la asociación política se encuentra en la hipotética condición pre-política en que se encuentran los individuos como tales, caracterizados únicamente por sus cualidades psico-físicas (fuerza física, experiencia, razones y pasiones, en el planteamiento de Hobbes) y no por su pertenencia étnica, lingüística o religiosa.

Es interesante observar que la expresión hobbesiana para caracterizar a tales individuos en el estado de naturaleza -"nacidos como los hongos"- adquiere un significado inverso al mito platónico de la autoctonía de los nacidos de la tierra (madre), por más que las dos "fábulas" puedan parecer a primera vista semejantes: en el estado de naturaleza, afirma Hobbes, es preciso considerar "a los hombres como si hubiesen surgido súbitamente de la tierra (como hongos) y se hubieran hecho adultos sin ninguna obligación de unos con otros" (De Cive, VIII, 1). Pero estos hombres no son "hermanos de sangre" dotados de características naturales de distinto valor que hayan de ser armonizadas en la polis ideal, sino individuos "sin ninguna obligación de unos con otros", que pueden considerar oportuno asociarse y formar un estado atendiendo únicamente a la mayor utilidad propia. Lo único que tienen en común son las facultades que distinguen a la naturaleza humana universal -fuerza física, experiencia, razón y pasiones- y la decisión de asociarse entre sí y formar una colectividad política, un poder que sea capaz de proporcionarles leyes comunes dotadas de sanciones eficaces, algo que depende exclusivamente de su voluntad. En línea de principio, ante una asociación concebida de esta forma, cabe la posibilidad de entrar o salir en cualquier momento mediante actos reciprocos de voluntad individual.

Este aspecto se observa de forma aun más clara en el Segundo tratado sobre el gobierno civil de Locke, donde se dice que ningún individuo está obligado a manifestar de forma explícita o tácita (es decir, aceptando la herencia paterna) la voluntad de pertenecer o no a una determinada colectividad política:

Así pues, resulta obvio, a la luz de la práctica de los gobiernos mismos, así como por la ley de la recta razón, que los hijos no nacen súbditos de ningún país ni de ningún gobierno. Hasta que alcanza la edad de la discreción se halla bajo la tutela y autoridad de sus padres, tras lo cual es un hombre libre con capacidad para elegir el gobierno al que se quiere someter, el cuerpo político al que desea pertenecer. Pues si un hijo de un inglés nacido en Francia goza de esa libertad para actuar así, es evidente que el que su padre sea súbdito de ese reino no supone para él ninguna obligación; ni mucho menos los pactos que hicieran sus ancestros. [...] Ningún hombre adquiere esa condición [de súbdito], salvo que ingrese en una comunidad por un compromiso positivo y una promesa y pacto expreso (Segundo tratado, § 118 y $\S 122$ ).

Como es obvio, no estoy sugiriendo que Locke fuera particularmente sensible al problema de las migraciones y al derecho a migrar cuando buscaba una cobertura histórica, y no meramente hipotética, a la idea de la razón, al contrato por el que se instituye la asociación política. Ello no es óbice para que la afirmación de que cada individuo empírico es el que puede escoger, aunque en la mayoría de los casos mediante un consentimiento tácito, el estado al que desea asociarse, sea un excelente punto de partida para argumentar a favor del derecho a migrar y de la ciudadanía por residencia. A este respecto Locke llega a declarar que mientras no exista una adhesión explícita del individuo a un estado todo hombre puede modificar su ciudadanía renunciando a la propiedad de que dispone en el estado del que ha sido hasta ese momento ciudadano en virtud del consenso tácito que subyace precisamente a dicha propiedad:

Puesto que el gobierno tiene una jurisdicción directa sobre la tierra y alcanza a quienes la poseen (antes de que se haya incorporado a la sociedad) sólo en la medida en que gocen de esas tierras o habiten en ellas, en tal caso, la obligación que se adquiere, en virtud de ese uso de la tierra, de someterse al gobierno, principia y termina con ese disfrute; de forma que siempre que el poseedor, que no ha dado más que su consentimiento tácito al gobierno, se deshaga de la posesión, mediante una donación, una venta, o de la manera que sea, tiene plena libertad de irse e incorporarse a otra república o juntarse con otros para dar inicio a otra nueva, in vacuis locis, en cualquier parte del mundo que encuentre libre y sin dueño (Segundo tratado, § 121).

A diferencia del caso de Locke, donde el derecho a la migración aparece como una consecuencia posible, pero no desarrollada, de la argumentación sobre el carácter a un tiempo histórico y convencional del fundamento de la 
obligación política, un siglo más tarde, con Kant, el tema empieza a adquirir cierta relevancia y autonomía cuando pasa a ser considerado como una de las condiciones necesarias de la paz duradera y, por tanto, de una sociedad mundial que sea capaz de dar un paso adelante en esa línea de progreso moral que representa el fin último en la historia universal del género humano. El tercer artículo definitivo de la Paz perpetua se refiere precisamente al derecho cosmopolita, esto es, al "derecho de un extranjero a no ser tratado hostilmente por el hecho de haber llegado al territorio de otro", que estará en vigor mientras el extranjero "se comporte amistosamente en su puesto" (Kant, 1998 , 27). Aunque también hay que recordar que la primera parte del argumento de Kant, en la que se establece la distinción entre el derecho a ser hospedado (Gastrecht) -que sería inexistente en cuanto derecho fundamental y si acaso precisaria "un contrato especialmente generoso, por el que se le hiciera huésped por cierto tiempo"- y derecho de visita (Besuchsrecht), que, por el contrario, si sería un derecho fundamental, ha dejado de ser suficientemente precisa.

Para nosotros, la idea de visita va a asociada a una permanencia temporal, sea cual sea su duración, que no supone un alto nivel de participación e integración en la sociedad visitada. Pero Kant la define así: el derecho de visita es el derecho que tiene todo ser humano de "presentarse a la sociedad [...] en virtud del derecho de propiedad en común de la superficie de la tierra, sobre la que los hombres no pueden extenderse hasta el infinito por ser una superficie esférica, teniendo que soportarse unos junto a otros y no teniendo nadie originariamente más derecho que otro a estar en un determinado lugar de la tierra" (Kant, 1998, 27). Así planteado, el derecho de visita resulta ser, de un lado, algo que se parece bastante al ius migrandi, abiertamente defendido por Francisco de Vitoria en 1539, y, de otro, se configura como la extensión a nivel planetario del impulso antropológico originario, esa "sociable insociabilidad" que lleva a cada individuo a buscar el aislamiento $y$, al mismo tiempo, a asociarse a los demás, y que explica las razones y modalidades por medio de las cuales existe el deber de abandonar la condición natural para constituir, en la primera de las etapas importantes que marcan el progreso de género humano, la sociedad civil.

La incertidumbre teórica de Kant respecto de la tesis mucho más explícita de Vitoria depende quizá de haber compro- bado, dos siglos más tarde, cuáles habían sido las consecuencias del ius migrandi tal como habia sido interpretado por las potencias europeas y sus compañias comerciales, potencias y compañias que el filósofo no deja de criticar con contundencia. El "derecho de visita" no debe dar pie a saqueos y expolios de los recursos autóctonos o, incluso, a la esclavización. Así pues, para que pueda convertirse en condición de paz y no de guerra, para que no se traduzca en conquista y ocupación violenta, el derecho cosmopolita de visita, o de migración, debe entenderse como un derecho estrictamente individual, del que no pueden ser titulares sujetos colectivos como los Estados, las tribus o las comunidades.

\section{Cuatro modelos CONTEMPoráneos de sociedad}

Este apresurado recorrido por algunos (pocos) clásicos del pensamiento político nos ha permitido acercarnos a algunas cuestiones recurrentes, a perplejidades y temores que desde tiempo inmemorial, como se suele decir, convierten en problemáticas las relaciones entre los grupos humanos, circunstancias que resultan todavía más evidentes con las migraciones contemporáneas. No es casualidad que la palabra latina hospes, huésped, tenga la misma raíz que el término que designa al enemigo, hostis. El extranjero, el otro, la persona que está enfrente se transforma en enemigo, en hostis, cuando se entra en guerra con él, y en hospes cuando es recibido de manera amistosa (de donde derivan términos como hostal, hospedaje, hotel, pero también obstáculo).

En los dos extremos de esta relación problemática hemos encontrado, de un lado, los mitos particularistas de la autoctonía $y$, de otro, los proyectos universalistas de la ciudadanía cosmopolita. Alguien podría señalar enseguida una asimetría en la que está implícito un juicio de valor, y replicar que el propio cosmopolitismo tiene más de mito que de proyecto. A lo cual yo respondería que el cosmopolitismo, entendido como constitucionalismo supranacional, es un proyecto ambicioso que puede llegar a convertirse en un mito si se le atribuyen virtudes milagrosas y regeneradoras, si adquiere una dimensión profética, si se piensa que su realización futura va a traer la superación de todos los males del mundo. Pero sigue siendo un proyecto racional en la medida en que se reconozca su carácter artificial 
como instrumento jurídico construido para regular una realidad, un conjunto de fenómenos que han adquirido una dimensión global. Esa dimensión a la que ya aludía Kant en 1795 en la conclusión del comentario al tercer artículo definitivo para la Paz perpetua: "Como se ha avanzado tanto en el establecimiento de una comunidad (más o menos estrecha) entre los pueblos de la tierra que la violación del derecho en un punto de la tierra repercute en todos los demás, la idea de un derecho cosmopolita no resulta una representación fantástica ni extravagante, sino que completa el código no escrito del derecho político y del derecho de gentes en un derecho público de la humanidad, siendo un complemento de la paz perpetua al constituirse en condición para una continua aproximación a ella" (Kant 1998, 30).

Por el contrario, los particularismos étnico-culturales tienen un carácter constitutivamente mítico. Son mentiras, como reconocía el propio Platón, aún considerándolas mentiras "nobles". La nobleza de los mitos originarios radicaba según Platón en su utilidad para la formación en los espíritus más simples de ese "espíritu de cuerpo", esa predisposición a la obediencia y esa capacidad de sacrificio en beneficio de los "hermanos" que, para resultar creible, precisa la identificación del otro, del extranjero, de quien no tiene el mismo origen, con el enemigo potencial. Sin embargo, a partir del momento en que, tras la aparición de los grandes estados territoriales modernos, la supervivencia de los grupos humanos ha dejado de asociarse a la rígida obediencia y a la observancia por parte de cada uno de los miembros de un código de deberes diseñado con el fin de evitar la disgregación interna, esta mentira pierde inmediatamente su carácter de necesidad y nobleza, convirtiéndose en mero pretexto de políticas de potencia y dominación recíproca, como demuestra la trágica historia de los nacionalismos de los siglos XIX y XX.

En todo caso, creo que las teorías jurídico-políticas de la segunda mitad del siglo XX han seguido interrogándose a partir de estas dos visiones contrapuestas de la convivencia humana -simplificando mucho: individualista-convencionalista (con la prioridad de los derechos sobre los deberes) y holista-culturalista (con la prioridad de los deberes sobre los derechos)-, disponiéndose a lo largo de la línea que podría dibujarse idealmente entre los dos extremos. Acercándome a la conclusión tomaré en consideración cuatro de ellas, sin ninguna intención de ofrecer un panorama completo: el (neo)utilitarismo, el (neo)comunitarismo, el (neo)republicanismo y el (neo)contractualismo que desemboca en el constitucionalismo de los derechos fundamentales. Es superfluo subrayar que en las respectivas posiciones sobre el derecho a migrar no hay nada que se derive de forma automática de cualquiera de ellas. No obstante, los modelos de sociedad que dichas teorías proponen permiten esbozar analíticamente -en virtud de un mero juicio de coherencia- la posición que en principio adoptarían en materia de derecho de migración. Prescindiendo de las diversas aportaciones específicas sobre el tema que nos interesa y que hacen referencia a estas cuatro teorías, me limitaré a realizar un austero ejercicio analítico.

\section{UTILITARISMO, REPUBLICANISMO Y COMUNITARISMO "LIBERAL"}

Como es sabido, el utilitarismo (del acto o de la regla) es tanto una teoría moral como una teoría política. Estas dos perspectivas están en tensión, porque el cálculo de costes y beneficios de cada individuo no coincide casi nunca con el cálculo social de los mismos. Aun siendo una teoría de orígenes individualistas -cada uno es el mejor juez de sus intereses-, la teoría social utilitarista presupone un macrosujeto sobre el que computar la utilidad y el daño. Desde este punto de vista, si se da incremento total del bienestar, si se produce una ganancia colectiva (¿comunitaria?), todo está bien, y tanto las cuestiones relativas a los derechos de las personas como los problemas redistributivos pasan a un segundo plano. Si el producto interno bruto aumenta, al final importa poco si los derechos fundamentales de las personas están garantizados o no, y si las desigualdades se vuelven más amplias. En este sentido, considero ejemplar la frase en la que Rawls sintetiza su crítica al utilitarismo: "el utilitarismo no se toma en serio la distinción entre las personas" $(1971, \mathrm{l}, 5)$.

Si esto es cierto, entonces lo mismo podrá decirse también y con más motivo de los migrantes y del derecho a migrar. Migrar no será un derecho de las personas, sino que la migración será promovida o impedida dependiendo de los beneficios sociales esperados. Si el trabajo de los extranjeros o de quienes provienen de otras regiones del estado hace aumentar la producción y en bienestar colectivo, entonces, bienvenidos sean los migrantes activos (a ser posible, sin 
cargas familiares); si, por el contrario, la migración produce costes superiores a los beneficios, entonces habrá que contenerla o prohibirla. Esto vale, evidentemente, tanto para los migrantes en entrada como para los que pretenden salir del estado.

Consideraciones análogas, aunque fundadas en motivaciones de carácter ético-cultural y no tanto económico, son coherentes con las teorias políticas republicanas. No hay duda de que no es nada fácil dar una definición de republicanismo que pueda abarcar las distintas versiones que a lo largo de estos últimos años han ido apareciendo, apelando a tradiciones distintas y hasta incompatibles, como son las de Aristóteles y Maquiavelo, Cicerón y Montesquieu, Harrington y Madison, por mencionar sólo algunos nombres. Se puede afirmar, sin embargo, que el énfasis de cualquier republicanismo (por mínimo y crítico que sea) recae sobre la virtud política del ciudadano, que se forma gradualmente y llega a madurar en un contexto político, institucional y cultural determinado, aunque entendido de forma no necesariamente excluyente respecto de las personas que provengan de otros contextos. Es en definitiva la tesis, probablemente la única que puede representar un común denominador entre los diferentes republicanismos, del "particularismo de los derechos" (tanto por su origen, como por su esfera de aplicación en la comunidad política), que podríamos resumir en palabras de Richard Bellamy (1999, 135): "los derechos tienen su fundamento o en la legislación o en los requisitos del sistema político, mas en ambos casos han de amoldarse a las circunstancias y a las caracteristicas de la comunidad y están sujetos a ser modificados. [...] El sistema no opera por medio de la garantía de derechos prepolíticos, sino favoreciendo su realización por medio de una cultura política cívica (civility) y el deber general de escuchar a la parte contraria". Partiendo de esta tesis de fondo se puede llegar a ser muy abiertos respecto de los migrantes, de sus razones y sufrimientos, pero, de nuevo, se les niega el derecho $y_{\text {, }}$ concretamente, el derecho inevitablemente "prepolítico" a la migración, cuando menos en la medida en que se trata de sujetos que (todavia) no pertenecen a la comunidad de diálogo que posee esa específica cultura política cívica. Los migrantes, en cuanto tales, $y$, sobre todo, las personas que provienen de realidades muy alejadas, son inevitablemente "analfabetos morales" respecto de la colectividad de destino. Sólo si la operación pedagógica llega a dar los frutos esperados podrán convertirse en ciudadanos y adquirir los derechos del ciudadano republicano. Al margen de la inquietud sobre la forma de integración buscada -la adhesión a un modelo predeterminado de virtud cívica-, queda por aclarar el hecho de que la decisión acerca de si y qué emigrantes acoger $y$, más tarde, acerca de la elección de los criterios y la valoración del resultado del proceso de integración corresponde a la comunidad de los ciudadanos "autóctonos".

También la visión comunitarista, que tomo aquí en sus versiones más abiertas al liberalismo - por ejemplo, la de Kymlic$\mathrm{ka}$, que no se presenta como una forma de comunitarismo, sino como un liberalismo adaptado al hecho del multiculturalismo-, me parece que ofrece un tratamiento ambiguo $y$, en último término, instrumental de la migración. Tomo como punto de referencia un ensayo recogido en Politics in Vernacular (2001), The new Debate over Minority Rights, donde Kymlicka retoma la tajante distinción entre societal cultures "autóctonas", que constituyen "national minorities" y minorias que en cambio derivan de las migraciones, que ya había sido apuntada en Multicultural Citizenship de 1995. Las minorías nacionales "deberían disponer de los mismos instrumentos de nation-building con que cuenta la nación mayoritaria, y deberían estar sujetas a los mismos límites liberales"; en otros términos, "lo que precisamos es una teoría coherente de las formas permitidas de nation-building dentro de las democracias liberales" (Kymlicka 2001, 29). En definitiva, la protección de la lengua como elemento central de la reproducción cultural y amplísima autonomía jurídico-política. Al contrario, con respecto a los inmigrantes, aunque entiende que sufren muchas "injusticias", Kymlicka considera que sus demandas al estado nacional deben estar limitadas al logro de "términos de integración más equitativos": lo que supone, en primer lugar, que "debemos admitir que la integración no puede producirse de la noche a la mañana" $y_{1}$ en segundo lugar, que debemos "asegurarnos que las instituciones a las que se ven inducidos (pressured) a integrarse garanticen un grado de respeto, reconocimiento y adaptación a las identidades y costumbres de los inmigrantes equivalentes al que se reserva a la identidad y a las costumbres del grupo mayoritario" (Kymlicka 2001, 30). Se excluye, sin embargo, que puedan llegar a configurarse como nuevas "national minorities".

Dos objeciones, de simple coherencia interna, se pueden dirigir inmediatamente a esta distinción entre minorías de autóctonos y de migrantes. La primera: cabría preguntar, 
con Aristóteles, a cuántas generaciones hay que remontarse para establecer una distinción como ésa. ¿Cuánto se tarda en volverse autóctonos? ¿Tres, cinco, siete generaciones? Pero, entonces, ¿qué motivo tendrían los migrantes para integrarse? ¿Acaso no les convendría esperar, para llegar a ser considerados ellos también como una minoría con derecho a su propia específica nation-building? La segunda objeción consiste en esta pregunta: si admitimos, con Kymlicka, que la comunidad cultural es decisiva para la "vida buena" de los individuos y para la reproducción de la lengua, los usos, las costumbres, la religión, etc., entonces, ¿por qué aspiramos (hipócritamente) a formas de integración que cortan de raíz, a medio o a largo plazo, en las segundas y terceras generaciones de migrantes, el árbol genealógico de su identidad cultural? Es evidente que una determinada manera de vestirse, la celebración de ciertos ritos, etc., pese a ser formalmente respetados por las instituciones públicas, no podrán sobrevivir sin el respaldo de su contexto cultural.

Quede claro que, como he reiterado en otros trabajos, desde mi punto de vista la "conservación ecológica" de las culturas, por decirlo con la bella fórmula de Habermas (1999), no es tan importante: al contrario, me parece fisiológico que las segundas generaciones de migrantes se alejen 0 rechacen abiertamente las costumbres de sus padres. En cambio, aun con los límites del liberalismo, esa conservación parecería importante, y mucho, para Kymlicka: si no, no habría razón para proteger a las minorías nacionales y para reconocerle la nation-building. Suponiendo que mi interpretación sea correcta, la pregunta que habría que hacer a Kymlicka es: si los migrantes pierden su derecho al bien más importante o, en todo caso, a uno de los bienes moralmente más importantes para un ser humano, es decir, el sentido de su pertenencia cultural, ¿entonces no acabarán perdiendo también, con ella, su humanidad, no se transformarán de personas en cosas, de fines en medios, como diría Kant? Y si es así, ¿qué es lo que queda en pie del liberalismo de Kymlicka? Y también, dicho sea de paso, ¿del liberalismo del Rawls de The Law of Peoples (1999)?

\section{Constitucionalismo mundial E IUS MigrandI}

Llego al final. Como ya he adelantado, a mi juicio, la teoría política más coherentemente abierta al reconocimiento del ius migrandi es la que deriva del contractualismo moderno y de la ilustración. Para ser más precisos, en ella este derecho no es más que la extensión más allá de las fronteras nacionales del derecho a la libre circulación de las personas. Respecto del derecho a la libre circulación, el derecho a migrar no es un añadido, una distorsión, sino la expresión más clara y rigurosa, la más coherente desde el punto de vista teórico con el marco de derechos del hombre y del ciudadano producido por el constitucionalismo derivado del contractualismo, y que se concreta en la idea de la ciudadanía vinculada a la mera residencia estable dentro de los límites de validez reconocidos en cada ordenamiento jurídico. $Y$ no es menos cierto lo contrario, esto es, que la negación del derecho a migrar, o su reconocimiento parcial, incompleto, como la establecida por el artículo 13 de la Declaración de 1948, supone una limitación injustificada en el plano teórico del derecho a la libre circulación de los seres humanos.

Obviamente, si esta perspectiva llegara a ser plenamente reconocida ello no supondría que el derecho fundamental a migrar no tuviera que ser objeto de regulación, como cualquier otro derecho, mediante leyes ordinarias, traduciéndose finalmente en políticas migratorias. Supondría, por el contrario, que su ejercicio habria de ser regulado para permitir su disfrute, es decir, para producir políticas migratorias orientadas a proporcionar a quien lo desee la posibilidad de migración legal en un plazo de tiempo razonable, en lugar de cerrar cada vez más los canales de la migración legal, abandonando en gran medida la gestión del fenómeno, al fin y al cabo imparable, a los "poderes salvajes", a la clandestinidad, a la esclavización de los migrantes a manos de organizaciones criminales y empleadores sin escrúpulos.

En última instancia no se trata más que de tomarse en serio, convirtiendo en realmente simétrico, ese ius migrandi al que se refería Francisco de Vitoria ya en el siglo XVI, un derecho que a su vez encontraba su fundamento en un ius communicationis ac societatis, en el marco de una concepción cosmopolita de las relaciones entre los seres humanos y los pueblos inspirada por la idea de fraternidad universal. No obstante, en la práctica esos derechos eran asimétricos y su afirmación cumplía una función ideológica para la justificación de la Conquista primero y después para la colonización del planeta por parte de las potencias europeas. Pero imaginemos qué es lo que pasaría si los

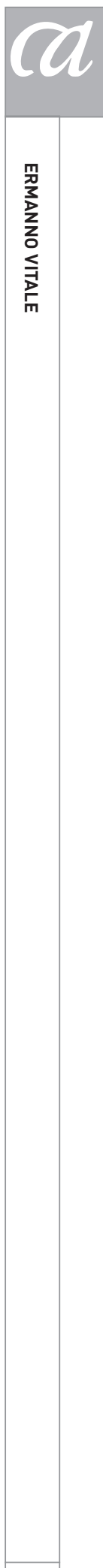


tomáramos en serio, al contrario de lo que en opinión de Luigi Ferrajoli sucede en nuestros dias:

Hoy la asimetría se ha invertido. [...] En el momento en que el ejercicio del derecho a emigrar se ha hecho una realidad para todos, y se ha convertido incluso en la única alternativa de vida para millones de seres humanos, no sólo ha caido en el olvido su fundamento histórico y jurídico en la tradición occidental, sino que ha pasado a ser reprimido con la misma ferocidad y energía con la que había sido esgrimido en los orígenes de la civilización moderna para la conquista y la colonización. Cuando llega la hora de tomar en serio su carácter universal, ese derecho se ha esfumado, volviéndose en su contrario. Es entonces cuando las fronteras de nuestros países han sido cerradas a cal y canto; cuando el fenómeno ha comenzado a crecer de forma progresiva e imparable, por el incremento exponencial de la desigualdad entre paises ricos y paises pobres, a consecuencia de los procesos de globalización" (Ferrajoli 2007, II, 351).

Alguien podría objetar que el análisis de Ferrajoli es demasiado simplista y esquemático, prescinde de la valoración de los distintos contextos históricos, encuentra en la globalización un culpable demasiado genérico $y_{\text {, }}$ por tanto, un blanco demasiado fácil hacia el que dirigir (¿demagógicamente?) las críticas. Quizá sea así, aunque la profunda crisis del paradigma de desarrollo al que nos enfrentamos en este momento histórico demuestra empíricamente -a través de las duras réplicas de la historia, como diría Bobbio- que una crítica tan radical como ésta ni es gratuita ni es inoportuna. Son muchos en nuestros días quienes se apresuran a criticar la deregulation y descubren, de la noche a la mañana, la necesidad de regular cuidadosamente la circulación de capitales y mercancias. Hablan, quizá sin ser del todo conscientes de ello, de la exigencia de promover el embrión de un constitucionalismo mundial. Pero para que esta regulación no se convierta en una nueva burbuja que al deshincharse, más pronto que tarde, deja tras de sí una sociedad mundial todavía más desigual e insegura, la primera libertad de circulación que tendrá que ser garantizada es la de las personas: "Es claro -puntualiza Ferrajoli- que el problema de la pobreza de los países subdesarrollados no se resuelve abriendo las fronteras, sino afrontando y resolviendo en su interior los problemas de desarrollo que padecen esos países. Pero no menos evidente es que Occidente no llegará a afrontar seriamente estos problemas mientras no llegue a sentirlos como propios. Y no los sentirá como propios mientras no se vea obligado a afrontar, tras haber invadido el mundo con sus conquistas primero y luego con sus promesas, la invasión de las poblaciones hambrientas que presionan todas sus fronteras. Siempre ha sido así en la historia de los derechos fundamentales. Estos derechos se otorgan a los excluidos sólo en el momento en que la presión sobre los incluidos se vuelve irresistible" (Ferrajoli 2007, II, 589). ¿Cuánto falta y hasta qué punto hay que llegar -me pregunto y os pregunto- para que esta presión empiece a resultar o a ser percibida como insoportable?
NOTA

* Traducción de Andrea Greppi.

\section{BIBLIOGRAFÍA CITADA}

Aristóteles (1993): Política, ed. cast. de C. García Gual y A. Pérez Jiménez, Madrid, Alianza.

Bellamy, Richard (1999): Liberalism and Pluralism, London, Routledge.

Recibido: 25 de febrero de 2009

Aceptado: 10 de abril de 2009
Bobbio, Norberto (2002): Teoría general de la política, Madrid, Trotta.
Ferrajoli, Luigi (2007): Principia iuris, Roma-Bari, Laterza.

Habermas, Jürgen (1999): "La lucha por el reconocimiento en el Estado democrático de derecho", trad. de J. C. Velasco, en La inclusión del otro, Paidós, Barcelona, 189-227.

Hegel, Georg Wilhelm Friedrich (2005): Enciclopedia de las ciencias filosóficas en compendio, ed. cast. de R. Valls Plana, Madrid, Alianza.

Hobbes, Thomas (2000): De cive: elementos filosóficos sobre el ciudadano, ed. cast. de C. Mellizo, Madrid, Alianza. 
Kant, Immanuel (1998): Sobre la paz perpetua, trad. cast. de J. Abellán, Tecnos, Madrid.

Kymlicka, Will (1995): Multicultural Citizenship, Oxford, Clarendon Press (trad. esp. Ciudadanía multicultural, Paidós, Barcelona, 1996).

Kymlicka, Will (2001): Politics in Vernacular, Oxford, Oxford University Press (trad. esp. Políticas vernáculas, Paidós, Barcelona, 2003).
Locke, John (2006): Segundo tratado sobre el gobierno civil, ed. cast. de C. Mellizo, Madrid, Tecnos.

Platón (1994), El político, edición castellana en El político; Critón; Menón, trad. de A. Ruiz de Elvira Prieto, M. Rico Gómez, A. González Laso, Madrid, Centro de Estudios Constitucionales.

Platón (2008), Las leyes, trad. cast. de M. Fernández Galiano, J. M. Pabón y Suárez de Urbina, Madrid, Alianza.
Platón (1998): La república, trad. cast. de M. Fernández Galiano, J. M. Pabón y Suárez de Urbina, Madrid, Alianza.

Rawls, John (1971): A Theory of Justice, Cambridge (Mass.), The Belknap Press of Harvard University Press (trad. esp. Teoría de la justicia, FCE, Barcelona, 1979).

Rawls, John (1999): The Law of Peoples, Cambridge (Mass.), Harvard U. P. (trad. esp. El derecho de gentes, Paidós, Barcelona, 2001). 